\begin{tabular}{|l|l|}
\hline & \\
\hline
\end{tabular}

SEÇÃO: ESTUDOS BAKHTINIANOS CONTEMPORÂNEOS

\title{
A relação entre a linguagem e a memória no atendimento clínico-terapêutico sob a perspectiva bakhtiniana
}

The relationship between language and memory in therapeutic clinical care from the Bakhtinian perspective

La relación entre el lenguaje y la memoria en la atención clínica terapéutica desde la perspectiva bakhtiniana

\section{Marcus Vinicius Borges Oliveira $^{1}$}

orcid.org/0000-0001-7120-4527 marcus.oliveira.fono@gmail.com

Recebido em: 15 abr. 2021. Aprovado em: 1 jul. 2021. Publicado em: 10 fev. 2022.

\section{(c) (i)}

Artigo está licenciado sob forma de uma licença Creative Commons Atribuição 4.0 Internacional.
Resumo: Este texto apresenta um percurso de estudos sobre a relação entre a linguagem e a memória dentro do escopo dos estudos bakhtinianos, inicialmente sobre as palavras na ponta da língua e, posteriormente, no estudo das dificuldades de encontrar palavras, principalmente, nas sindromes demenciais. Neste contexto, busco refletir com o Circulo de Bakhtin sobre o elo entre o caráter individual e coletivo das memórias e aponto para a relevância dessa discussão no entendimento das fronteiras entre o normal e o patológico na relação entre linguagem e memória, sobretudo no envelhecimento.

Palavras-chave: Memória. Bakhtin. Linguagem. Doença de Alzheimer. Esquecimentos.

Abstract: This paper presents a course of studies on the relation between language and memory within the scope of Bakhtinian studies, initially on the tip-of-the-tongue phenomena and later studying word finding difficulties, especially in dementia syndromes. In this context, I reflect with Bakhtin's Circle on the link between the character individual and collective of memories and I point out the relevance of that discussion in understanding the boundaries between normal and pathological in the relation between language and memory, especially in aging. Keywords: Memory. Bakhtin. Language. Alzheimer Disease. Forgetfulness.

Resumen: Este texto narra un curso de estudios sobre la relación entre lenguaje y memoria en el ámbito de los estudios bakhtinianos, inicialmente sobre palabras en la punta de la lengua y luego estudiando las dificultades para encontrar palabras, especialmente en las sindromes demenciales. En este contexto, busco reflexionar con el Círculo de Bakhtin sobre el vínculo entre el carácter individual y colectivo de los recuerdos y señalo la relevancia de esta discusión para comprender los límites entre lo normal y lo patológico en la relación entre lenguaje y memoria, especialmente en el envejecimiento.

Palabras clave: Memoria. Bakhtin. Lenguaje. Enfermedad de Alzheimer. Olvido.

\section{Introdução}

Este texto narra um percurso de estudos da relação entre a linguagem e a memória tomando como base teórica as reflexões provenientes do Círculo de Bakhtin e do filósofo italiano Augusto Ponzio. Inicialmente, apresentaremos resumidamente sobre a relação entre memória e linguagem nas palavras que ficam na "ponta da língua", para posteriormente, nos adentrarmos na principal temática do artigo, que diz respeito às reflexões 
mais recentes baseadas no trabalho com as demências, em que se faz importante destacar as relações entre a memória coletiva e a memória individual, sempre em diálogo com o pensamento do Círculo de Bakhtin. Por fim, baseado no estudo de um caso clínico, refletiremos sobre a demência de Alzheimer e as memórias compartilhadas, os esquecimentos dos nomes próprios e as estratégias clínico-terapêuticas que podem ser utilizadas no atendimento fonoaudiológico.

\section{A relação entre linguagem e memória nas palavras na "ponta da língua"}

No período entre 2011 e 2015, em virtude do doutorado, dediquei-me aos estudos do fenômeno das palavras na ponta da língua, conhecido na literatura especializada como TOT (Tip Of the Tongue); a falta da palavra de maneira tão especifica pode ser encarada tanto como efeito de um esquecimento quanto como de uma falha no acesso lexical, atrelado ao campo de estudos de que se parte. Essa complexidade do fenômeno TOT foi metaforizada, na tese, ${ }^{2}$ como a "ponta do iceberg", já que seria a interface sensivel de processos subjacentes muito mais amplos e complexos que se dão na relação entre diversas funções psicológicas superiores, tais como atenção, percepção, linguagem e memória. Além disso, apenas para complementar a descrição desse fenômeno, devemos nos lembrar de que se trata não somente da ausência da palavra, mas também da percepção dessa ausência - como bem coloca Willian James (1890), há mais de um século. Trata-se de um vazio imensamente ativo capaz de nos fazer rejeitar outras palavras que nos são propostas.

Ainda no contexto da referida tese, há um capítulo específico, dedicado às reflexões teóricas baseadas no Círculo de Bakhtin, chamado "a palavra na ponta-da-palavra", título sugerido por Augusto Ponzio, ${ }^{3}$ que tratou da aproximação dos TOTs com uma abordagem dialógica orientada pelas ideias do Círculo de Bakhtin. Desse capítulo, destaco algumas das reflexões já apresentadas naquele momento sobre a relação entre a linguagem, a memória e o esquecimento:

a) ao distinguir sinal e signo, significado e tema, identificação e compreensão, o silenciar e o calar, estamos lidando com dois planos: um que trata da reprodutibilidade da língua e o outro, da irreprodutibilidade da enunciação, que são permitidos, dentre outros fatores, pelo dinamismo e atualização da memória. Considerando que, para Bakhtin (1997), toda palavra não pode deixar de se orientar pelo já dito, pelos seus usos anteriores, a réplica a um determinado enunciado não se faz somente no tempo presente, em uma espécie de microdiálogo, mas também com as memórias que se relacionam com aquele enunciado dentro de um grande diálogo;

b) para compreender as possiveis motivações que podem determinar o não surgimento de uma palavra, é importante ainda refletir sobre as diferentes condições histórico-sociais que podem dar às palavras um estatuto de oficiais, bem-aceitas dentro de um determinado discurso, ou de não oficiais. Para Ponzio (2013, informação verbal), a palavra evoca uma série de associações que o sujeito não controla; da qual nem ao menos suspeita. Essas associações, obviamente, seriam não oficiais para o sujeito, encontrando dificuldades em emergir como discurso oficial (VOLÓCHINOV, 2017). Além disso, de acordo com Ponzio (2010), aludindo a Bakhtin, o domínio da palavra é ilusório, pois a palavra tem natureza condominial; ou seja, não tem dono. Sendo assim, quanto maior for a nossa necessidade de controlar a palavra mais nos sentiremos traídos no momento em que ela resolver não aparecer;

\footnotetext{
2 A tese Palavras na Ponta-da-Lingua: Uma abordagem Neurolinguística, orientada pela Prof. Dra. Rosana do Carmo Novaes Pinto, foi defendida em 2015 e, posteriormente, revisada e publicada como livro com mesmo título em 2017.

3 Participei de um estágio de pesquisa no exterior intitulado "As palavras na ponta da língua: Inferências para o estudo das relações entre linguagem, memória e consciência", na universidade de Bari, com Augusto Ponzio e Susan Petrilli, em 2013. Foram apresentadas duas palestras sobre o tema, uma realizada em conjunto, em Campinas, chamada "Memória da palavra e memória do falante" e outra apresentada somente por mim, em Bari, chamada "A palavra na ponta da palavra". Nos referenciamentos a Ponzio (2013, informação verbal), faço alusão a minhas notas pessoais obtidas nesta ocasião.
} 
c) da relação entre palavra própria e palavra alheia, considerando que, para Bakhtin, a palavra não se esquece de seu próprio caminho na língua e não pode se libertar dos contextos concretos pelos quais passou, podemos refletir sobre a dupla natureza do signo: o fato de que se relaciona à língua e a sua história, diacronicamente - isto é, aos sentidos que são cristalizados na lingua pelo trabalho de seus falantes (GERALDI, 1991) - e à relação entre a língua e o sujeito, em um dado momento histórico-cultural, sincronicamente, e perpassada por todas as experiências do sujeito com a heterogeneidade da linguagem: as variantes socioculturais, os graus de formalidade dos registros, dentre outros (OLIVEIRA, 2017);

d) a partir da reflexão sobre identidade e alteridade, sobretudo na obra de Bakhtin (1997), Ponzio (2007, 2013, informação verbal) define duas instâncias da memória - uma ligada ao ato de memorizar e outra ligada ao de recordar. De acordo com o autor, a primeira pertence ao sujeito; ou seja, ocorre de acordo com a sua vontade, e é por ele controlada. Ponzio relaciona essa instância à "identidade". Já a segunda instância, segundo o autor, refere-se à recordação, que se dá pela alteridade. Nessa última instância, o sujeito é impelido, involuntariamente, a lembrar-se. Também se faz necessário retomar aqui o discurso de que a memória não é a volta de um passado em direção ao presente, mas uma interpretação, ou reconfiguração, que parte do presente em direção ao passado ou mesmo ao futuro.

Alguns desses pontos foram retomados recentemente em uma outra pesquisa de nossa autoria, já não voltada para os TOTs, mas para as pessoas que lidam com as dificuldades de encontrar palavras - em sua maioria diagnosticadas como portadoras de síndromes demenciais lidando com diferentes graus de esquecimentos. ${ }^{4}$ Nesse estudo, em desenvolvimento, a discussão sobre a relação entre linguagem e memória (e esquecimento) tem papel principal, para além das dificuldades específicas com a palavra, aludindo, principalmente, para a relação entre o caráter coletivo e individual das memórias, que discutiremos a seguir.

\section{As demências e a relação entre a} memória coletiva e a memória individual

Muito se discute sobre as demências, pelo seu aspecto inesperado, que surpreende pela forma como os esquecimentos vão se tornando progressivamente incapacitantes, geralmente percebidos por familiares e amigos, aqueles que, de certa forma, não estão acostumados a lidar com os (des)caminhos da memória. Um outro fator que coloca as demências no centro das discussões é a sua relação com a identidade, o que tem sido bastante abordado, inclusive, no campo da arte. Foi ao assistir ao filme Para sempre Alice (GLATZER, WESTMORELAND, 2014), uma aluna me questionou como seria possivel alguém esquecer-se de si mesmo.

Quando o médico chamado Alois Alzheimer trabalhava com a paciente que, digamos assim, levou-o a descrever essa síndrome demencial, a qual posteriormente levou o seu nome, Auguste D. tinha apenas 51 anos. A perda da memória, em seu estágio avançado, levou-a a dizer que havia se perdido de si mesma, ou seja, conduziu-a a um certo esquecimento de si, o que nos leva a refletir sobre uma das principais características das demências: o impacto da (perda da) memória em relação à subjetividade.

Naquele período, a demência era claramente definida como uma patologia, e não uma consequência do envelhecimento. No entanto, de acordo com Groisman:

Um novo olhar parece ter se constituido sobre
a velhice, nas duas últimas décadas do século
XX, e o caso da Doença de Alzheimer exempli-
fica perfeitamente isso. Os pequenos desvios
parecem ser cada vez menos tolerados, as
dificuldades e a dependência causadas pelo
envelhecimento passam a ser patologizadas e 
medicalizáveis. Mas não deixa de ser curioso, também, que justamente o diagnóstico seja um dos pontos mais problemáticos da doença de Alzheimer. Só se pode chegar a um diagnóstico com alguma margem de precisão com exames anatomopatológicos do cérebro, após a morte do paciente. Mesmo assim, houve casos de pessoas que possuiam as lesões caracteristicas da doença e que não teriam desenvolvido seus sintomas (Robertson, op. cit.). Mesmo com a utilização de testes genéticos, os diagnósticos feitos são prováveis ou presumiveis. Temos, portanto, uma epidemia de diagnósticos prováveis de uma doença de etiologia ainda desconhecida (GROISMAN, 2002, p. 76).

A demência, na condição de entidade nosológica, tem sido analisada pelo prisma individual, ligado à (perda da) identidade. No entanto, do ponto de vista da memória coletiva, aqui entendida conforme Halbwachs (2017), pouco se reflete sobre os efeitos desses esquecimentos em relação a uma arquitetura coletiva da memória.

Lembremos que, como afirma Wertsch (2010, p. 1), existe um distanciamento entre as "publicações de psicólogos que se propõem a abordar o tópico geral da memória humana", que frequentemente deixam de lado as formas coletivas de memória e os "tratamentos da memória coletiva por historiadores ou sociólogos que demonstram ter pouco conhecimento da psicologia da memória individual".

Considerando que a teorização produzida pelo Círculo de Bakhtin pode ajudar a vislumbrar o(s) elo(s) entre a memória individual e a coletiva, uma vez que trata do terreno interindividual sígnico à consciência individual como um fato sociológico, acreditamos que a reflexão dentro do campo de estudos bakhtinianos pode nos fazer avançar na compreensão das margens entre o normal e o patológico no que diz respeito ao esquecimento.

A partir do conceito de arquitetônica é possivel refletir sobre aquilo que Amorim (2009) chama de memória da enunciação, já que a arquitetônica bakhtiniana pressupõe diferentes momentos e posições que se relacionam a diferentes qualidades de memória, possibilitando, portanto, inferências sobre a memória compartilhada e, sobretudo, sobre o excedente de memória que o outro tem sobre mim (e eu sobre ele). Nossas memórias, mesmo que compartilhadas, jamais coincidem, dado que um mesmo evento recebe diferentes avaliações axiológicas em decorrência de nosso posicionamento na enunciação.

Sendo assim, as diferentes posições que ocupamos na enunciação produzem qualidades de memória distintas. Se retomarmos como a arquitetônica bakhtiniana é apresentada no primeiro escrito de Bakhtin (2010), Para uma filosofia do ato responsável, podemos refletir melhor sobre o efeito dessas diferentes posições:

O princípio arquitetônico supremo do mundo
real do ato é a contraposição concreta, arqui-
tetonicamente válida, entre eu e outro. A vida
conhece dois centros de valores, diferentes por
principio, mas correlatos entre si: o eu e o outro,
e em torno destes centros se distribuem e se
dispõem todos os momentos concretos do exis-
tir. Um mesmo objeto, idêntico por conteúdo, é
um momento do existir que apresenta aspecto
valorativo diferente, quando correlacionado co-
migo ou com o outro [.... (BAKHTIN, 2010, p. 142).

Bakhtin caracteriza os momentos dessa arquitetônica em termos de alteridade. Em cada espaço temporal, em que o eu-outro seja centro, estarão inevitavelmente dispostos o eu-para-mim, o outro-para-mim e o eu-para-outro. É importante ressaltar que o eu e o outro não são intercambiáveis, como apresentado comumente dentro de certas teorias da linguística/comunicação, mas acontecem no mesmo momento enunciativo, e no qual perceberemos que essas memórias (em diferentes perspectivas) se entrelaçam no discurso.

O eu é precisamente aquele que não é o outro, o eu-único que ocupa aquela posição singular em dado espaço e tempo, sem álibis (BAKHTIN, 2010). Em cada uma dessas posições ("eu", "outro"), podemos distinguir a memória que tenho de mim, aquela que tenho do outro e, principalmente, a que o outro tem de mim. De acordo com Bakhtin:

A memória que tenho do outro e de sua vida
difere, em sua essência, da contemplação e da
lembrança da minha vida: essa memória vê a
vida e seu conteúdo de uma forma diferente,
e apenas ela é produtiva (a lembrança e a
observação da minha própria vida podem for-
necer-me os elementos de um conteúdo, mas
não podem suscitar uma atividade geradora da
forma e do acabamento) (BAKHTIN, 1997, p. 122).

Dentro dessa arquitetônica, implica-se a ideia de que a memória do outro confere acabamento, 
situa-se no passado e tem caráter estético, e, por isso, a memória do herói é sempre inacabada e se perfaz no futuro. Assim, de acordo com Bakhtin, "para mim, a memória é memória do futuro, para o outro, memória do passado" (BAKHTIN, 1997, p. 140).

[...] o homem tem uma necessidade estética absoluta do outro, da sua visão e da sua memória; memória que o junta e o unifica e que é a única capaz de lhe proporcionar um acabamento externo. Nossa individualidade não teria existência se o outro não a criasse. A memória estética é produtiva: ela gera o homem exterior pela primeira vez num novo plano da existência (BAKHTIN, 1997, p. 167)

Vejamos a análise de um dado de minha pesquisa atual, retirado de sessões fonoaudiológicas que ocorreram no, Centro de Referência Estadual de Atenção à Saúde do Idoso (CREASI). ${ }^{5}$

\section{Análise do atendimento clínico-}

\section{terapêutico}

A paciente, dona Arlinda, tinha 84 anos quando nos conhecemos. Trata-se de uma pessoa extre- mamente simples, carioca, que gosta de dançar e de sair de casa, profundamente religiosa, lidando com seus esquecimentos cada vez mais frequentes. Suas principais queixas estão relacionadas à dificuldade de encontrar palavras, principalmente nomes próprios, o que atrapalha, principalmente, as suas orações. Conforme veremos adiante, a paciente tinha especial carinho por um neto, de quem sempre se esquecia do nome.

O seu prontuário deixa bem explícito que a paciente sofre de esquecimentos que progressivamente vêm incomodando a sua vida. Sua principal dificuldade nos exames está no quesito memória recente. O protocolo datado de 2012 indica que ela teria demência de Alzheimer há quatro anos, tendo como principal sintoma cognitivo o declínio de memória recente, considerado progressivo com piora nos últimos meses.

Vejamos alguns dados que nos dão a dimensão do estado de esquecimento de dona Arlinda (Quadro 1).

Quadro 1 - Recorte de sessão fonoaudiológica $1^{6}$

\begin{tabular}{|c|c|c|c|}
\hline \multicolumn{2}{|c|}{$\begin{array}{l}\text { Data da sessão: } \\
16 / 05 / 2018\end{array}$} & \multicolumn{2}{|c|}{$\begin{array}{l}\text { Participantes: Fonoaudiólogo responsável (MVB), } \\
\text { Arlinda (A), Estagiárias (AL) e (L) }\end{array}$} \\
\hline & & \multicolumn{2}{|c|}{$\begin{array}{c}\text { Contexto Situacional - Trabalho com fotos das viagens de Arlinda, neste } \\
\text { episódio MVB e Arlinda falam das fotos da viagem à Jerusalém }\end{array}$} \\
\hline MVB & 01 & Huuum... Onde é aqui? & Procura outra foto no álbum. \\
\hline A & 02 & $\begin{array}{l}\text { Olha... agor... Sabe que eu já esqueci assim? Os } \\
\text { nome do lugar... E... eu tenho até um álbum que... } \\
\text { eu estou assim dento do mar vermelho. Eu não } \\
\text { sei aonde foi... porque o pessoal fica pedindo } \\
\text { pra ver né? Ai já viu... Tem um álbum que... eu to } \\
\text { em um bocado de lugar assim no mar vermelho. } \\
\text { Assim... É... Esse bispo me rebatizou a mim e as } \\
\text { outras pessoas, que foram também na viagem. }\end{array}$ & \\
\hline MVB & 03 & $\begin{array}{l}\text { Aaaaaah... A senhora foi rebatizada no mar ver- } \\
\text { melho. }\end{array}$ & \\
\hline A & 04 & É... No mar vermelho. & \\
\hline MVB & 05 & Dona A., a senhora é muito chique mermo viu. & \\
\hline
\end{tabular}

5 Esta pesquisa intitulada "Processos linguísticos cognitivos subjacentes às dificuldades de encontrar palavras" foi aprovada pelo comitê de ética e pesquisa sobre parecer de número 2.547.410. Ressalto que os nomes dos pacientes e dos seus familiares utilizados neste texto são todos fictícios.

6 Nesse quadro, a primeira coluna diz respeito aos participantes, a segunda aos turnos transcritos, a terceira é uma transcrição verbal, e a quarta coluna descreve movimentos não verbais que consideramos importante para o melhor entendimento dos diálogos 


\begin{tabular}{|c|c|c|c|}
\hline \multicolumn{2}{|c|}{$\begin{array}{l}\text { Data da sessão: } \\
16 / 05 / 2018\end{array}$} & \multicolumn{2}{|c|}{$\begin{array}{l}\text { Participantes: Fonoaudiólogo responsável (MVB), } \\
\text { Arlinda (A), Estagiárias (AL) e (L) }\end{array}$} \\
\hline & & \multicolumn{2}{|c|}{$\begin{array}{l}\text { Contexto Situacional - Trabalho com fotos das viagens de Arlinda, neste } \\
\text { episódio MVB e Arlinda falam das fotos da viagem à Jerusalém }\end{array}$} \\
\hline A & 06 & É aí tem... & Apontando pro álbum. \\
\hline MVB & 07 & Rebatizada no mar vermelho! & \\
\hline A & 08 & $\begin{array}{l}\text { Ai tem... Pedaço que a... Atualmente tá sendo } \\
\text { bombardeado. Por causa dessa viagem do... } \\
\text { Desse presidente... Olha! Eu até me arrepio, esse } \\
\text { presidente americano miserável! Que botou } \\
\text { uma... Como é? Botou um baru... Um negócio lá. } \\
\text { Que eu até me esqueci o nome. Que agora tá } \\
\text { tendo a guerra deles lá. Uma confusão danada, } \\
\text { e... Nós já andamos tanto nesses lugares... }\end{array}$ & $\begin{array}{l}\text { Olhando pros braços. } \\
\text { Olhando pro álbum com uma } \\
\text { expressão nostálgica. }\end{array}$ \\
\hline MVB & 09 & Aqui? & Mostrando outra foto. \\
\hline A & 10 & $\dot{\mathrm{E}}$. & \\
\hline MVB & 11 & Deve ter sido uma igreja também né? & \\
\hline A & 12 & $\dot{E}_{\ldots} .$. & \\
\hline MVB & 13 & Isso aqui é tudo Jerusalém? & \\
\hline A & 14 & $\begin{array}{l}\text { É.. tudo Jeru.. ai é tudo Jerusalém. Só o resto eu } \\
\text { acho que não é. }\end{array}$ & \\
\hline MVB & 15 & Olha que igreja bonita hein? & \\
\hline A & 16 & $\begin{array}{l}\text { Muito bonita! Tem... Lugar aí que... Fo.. é o lugar } \\
\text { onde... Tem aquele buraco onde botaram o... } \\
\text { Botaram... }\end{array}$ & $\begin{array}{l}\text { Olha pra MVB por debaixo } \\
\text { do óculos como se estivesse } \\
\text { esquecido a palavra e depois } \\
\text { sorri. } \\
\text { Com o queixo apoiado nas } \\
\text { mãos olhando pra MVB. }\end{array}$ \\
\hline MVB & 17 & Botaram quem? & \\
\hline A & 18 & $\begin{array}{l}\text { Que morreu... Que mataram... Que... não é padre } \\
\text { não. Que mataram... } \\
\text { Mataram Jesus! } \\
\text { Ai tem o lugar que botaram Jesus, ai a gente vai } \\
\text { passa a mão por cima, reza... } \\
\text { Coisa muito legal! Muito legal mesmo! }\end{array}$ & $\begin{array}{l}\text { Bate as mãos na mesa quan- } \\
\text { do lembra a palavra. } \\
\text { Alisando a mesa. }\end{array}$ \\
\hline
\end{tabular}

Fonte: Elaborado pelo autor (2021). 
Inicialmente, dona Arlinda se queixa de não saber os nomes dos lugares, posteriormente, ao fazer comentários sobre o presidente dos EUA, esquece-se da palavra "embaixada", comentaremos sobre isso adiante. No turno 08, ocorre outro esquecimento bastante curioso por se tratar da figura central da doutrina Cristã, sobre a qual se desenrola não somente a conversa, mas toda a fé de dona Arlinda. É relevante que esse esquecimento aconteça justamente no sintagma "buraco onde botaram...", deixando nítida uma sensação de incompletude.

No turno 18, primeiro ela diz que ele morreu, mas logo diz foi morto, estabelecendo uma diferença que possibilita o aparecimento da palavra. Mas, antes, dentro do mesmo campo semântico, vem a palavra padre. Como alerta Ponzio (2010), a palavra nos trai, nos faz crer que somos donos, mas por vezes nos faltam. Para dona Arlinda, esquecer o nome Jesus era quase um pecado. Existe algo extremamente curioso na relação entre memória e esquecimento que parece zombar da humanidade, já que "por vezes, esquecemos aquilo que gostariamos de lembrar ou lembramos de coisas que gostariamos de ter esquecido" (OLIVEIRA, 2015, p. 102).

Como podemos perceber da obra de Maurice Halbwachs (2017), é impossivel conceber que recordações prescindam do caráter social e coletivo das quais fazem parte. A existência de uma memória coletiva não se dá em contraposição a uma memória individual, mas composicionalmente com ela, considerando as diferentes avaliações oriundas dos diferentes posicionamentos em torno do objeto a ser lembrado. De acordo com o autor:

Recorremos a testemunhos para reforçar ou enfraquecer e também para completar o que

\begin{abstract}
sabemos de um evento sobre o qual já temos alguma informação, embora muitas circunstâncias a ele relativas permaneçam obscuras para nós. O primeiro testemunho a que podemos recorrer será sempre o nosso. [...] Assim, quando voltamos a uma cidade em que já haviamos estado, o que percebemos nos ajuda a reconstituir um quadro de que muitas partes foram esquecidas. Se o que vemos hoje toma lugar no quadro de referências de nossas lembranças antigas, inversamente essas lembranças se adaptam ao conjunto de nossas percepções do presente. E como se estivéssemos diante de muitos testemunhos (HALBWACHS, 2017, p. 29).
\end{abstract}

Como argumentamos, as memórias sobre os eventos estão em diálogo na enunciação, elas podem se complementar, se certificar, se contrastar, se destoar, se tensionar etc. No caso do diálogo acima (Quadro 1), somente depois dessa conversa, em pesquisa pela internet, descobri que, no dia 14 de maio de 2018, os EUA tinham inaugurado uma embaixada em Jerusalém. Além disso, naquele momento, não tinha conhecimento sobre a Pedra da Unção e nem aventava a possibilidade de ali estar a tumba onde fora colocado Jesus Cristo (Santo Sepulcro). Talvez, se tivesse esse conjunto de informações poderia ter conduzido a sessão para um outro caminho, no turno 8, falando sobre a embaixada e o presidente Trump; ainda assim, falamos de nossas recordações sobre o Mar Vermelho, Jerusalém, Igreja. Por outro lado, acredito que o fato de que eu não sabia que ali estava Jesus (turno 17) levou Arlinda a buscar a palavra com mais afinco.

Dando continuidade a essa reflexão, gostaríamos de discutir brevemente aquilo que mais incomodava dona Arlinda, o esquecimento de nomes próprios, principalmente quando era do neto que tinha ajudado a criar, com quem tinha uma relação de amor muito forte, como podemos ver abaixo: 
Quadro 2 - Recorte de sessão fonoaudiológica 2

\begin{tabular}{|c|c|c|c|}
\hline \multicolumn{2}{|c|}{$\begin{array}{l}\text { Data da sessão: } \\
\text { 06/06/2018 }\end{array}$} & \multicolumn{2}{|c|}{ Participantes: Fonoaudiólogo responsável (MVB), Arlinda (A), Estagiárias (AL) e (L) } \\
\hline & & \multicolumn{2}{|c|}{$\begin{array}{l}\text { Contexto Situacional - Inicio de sessão fonoaudiológica, } \\
\text { MVB e Dona Arlinda conversam sobre os esquecimentos }\end{array}$} \\
\hline MVB & 01 & Te incomoda esse esquecimento, dona Arlinda? & \\
\hline A & 02 & $\begin{array}{l}\text { Ah, às vezes incomoda né? Porque... tem coisa assim, que eu } \\
\text { quero lembrar... a minha família mesmo né? E... às veze... Olha eu } \\
\text { sou muito católica. Eu rezo todo dia, começo a rezar as qua- } \\
\text { tro da manhã e... eu rezo pra minha familia toda. As veze eu tô } \\
\text { rezando, esqueço o nome do... meus neto! Esqueço... o nome do } \\
\text { bisneto! } \\
\text { E fico assim naquela de horror quando acabo de rezar... Eu vou } \\
\text { assim pra procurar lembrar... num lembro! } \\
\text { E é meus neto que eu... praticamente eu convivi a vida toda! } \\
\text { Que... ele moram lá no Rio, mas co... Constantemente eu tô lá } \\
\text { no Rio... com eles! Mas... me esqueço. E... tem um mesmo que... } \\
\text { quem acompanha mais ele, sou eu. Que ele é... é do exército! }\end{array}$ & $\begin{array}{l}\text { Falando em tom de } \\
\text { desapontamento. } \\
\text { Em tom de desa- } \\
\text { pontamento. }\end{array}$ \\
\hline MVB & 03 & Eu já vi a foto. & \\
\hline A & 04 & $\begin{array}{l}\text { Então... é, comé?... Cada vez que eu rezo, ele mermo eu esque- } \\
\text { ço tanto o nome dele, não consigo lembrar! Eu lembro o nome } \\
\text { da... da filha dele. Lembro o nome do filho dele. Mas não lembro } \\
\text { dele! Ai depois eu... teve um... agora um dia desse que eu... eu } \\
\text { liguei pra minha filha... perguntando "Luíza, como é o nome do } \\
\text { teu filho... que é do exército?" Aí ela brigando comigo, "mãe, } \\
\text { você não tá lembrando o nome dele não?, você não reza pra ele } \\
\text { todo dia, não me diz que reza pra ele..." aí eu falei, "eu rezo... mas } \\
\text { num... num tô lembrando o nome dele". O mais velho, eu lembro, } \\
\text { mas o dele eu não lembro. E tem as pessoas mesmo que... são } \\
\text { muito minha amigas, tudo. Mas... eu esqueço, não sei falar o } \\
\text { nome. }\end{array}$ & $\begin{array}{l}\text { Em tom de desa- } \\
\text { pontamento. }\end{array}$ \\
\hline & & {$[\ldots]$} & \\
\hline MVB & 05 & É um desses nomes que a senhora esquece de vez em quando... & \\
\hline A & 06 & $\begin{array}{l}\text { Esqueço, pois é. É... Foi interessante! Desde novinho foi.. o que } \\
\text { mais... ficou comigo. Quando minha filha veio morar aqui... Eu } \\
\text { até... comprei um berço pra botar... esse... neto pra dormir junto } \\
\text { comigo assim... do lado da minha cama. E... agora... ele quando } \\
\text { foi estudar, tudo eu que procurava pra ele... Ele quando fez o } \\
\text { curso pro exército... Eu procurava pra ele... Quando ele foi se for- } \\
\text { mar, teve a primeira formatura ele, eu é que fui... dar... pra resol- } \\
\text { ver o problema da mãe que não pode ir. Quando foi o segundo... } \\
\text { curso dele que ele se formou eu é que fui... pra representar a } \\
\text { mãe dele, o pai dele. E tudo, tudo! Ele... foi morar em Recife, eu } \\
\text { é que ia visitar ele. Ele foi morar em Minas, eu é que ia visitar ele. } \\
\text { Enfim, todo lugar que... que ele ia... eu que ia... visitar! Que a mãe } \\
\text { e o pai nunca podia ir... Então... Eu que tava sempre... junto com } \\
\text { ele... Agora eu esqueço tanto o nome dele que eu não... }\end{array}$ & \\
\hline MVB & 07 & E agora, a senhora tá lembrando o nome dele? & \\
\hline
\end{tabular}




\begin{tabular}{|l|l|l|l|}
\hline $\begin{array}{c}\text { Data da sessão: } \\
\text { o6/06/2018 }\end{array}$ & Participantes: Fonoaudiólogo responsável (MVB), Arlinda (A), Estagiárias (AL) e (L) \\
\hline & 08 & Agora? Eu não to lembrando... Tô lembrada sim! & $\begin{array}{r}\text { Contexto Situacional - Início de sessão fonoaudiológica, } \\
\text { MVB e Dona Arlinda conversam sobre os esquecimentos }\end{array}$ \\
\hline A & 09 & Como é que ele chama? & \\
\hline MVB & 10 & $\begin{array}{l}\text { Peraí.. Ah, Raimundo e Rafael. Eu lembrei por causa do irmão } \\
\text { mais velho, que é Raimundo. É Raimundo e Rafael. Então eu... sei } \\
\text { lá... penso em nem procurar tratamento mais nenhum... }\end{array}$ & Sorri. \\
\hline A & 11 & Vai abandonar a gente? & Sorri. \\
\hline MVB & 12 & Porque... Tô sempre assim nessa de... horror! & Sorri. \\
\hline A & 13 & Nessa de horror... \\
\hline MVB & 13 & & \\
\hline A & 14 & & \\
\hline
\end{tabular}

Fonte: Elaborado pelo autor (2021).

O esquecimento de nomes próprios é um grande tema discutido na literatura sobre as palavras na ponta da língua. De acordo com Hanley (2014), existem evidências claras de que os idosos têm mais TOTs com nomes próprios do que os mais jovens; além disso, também existem evidências de que os sujeitos com demência de Alzheimer, no período inicial, têm problemas particulares com nomes próprios.

No caso de dona Arlinda, é particularmente interessante que o nome esquecido seja um que tenha tantas associações presentes, uma rede de informações inferenciais e afetivas, em uma espécie de traição na própria casa (PONZIO, 2010). Lidar com essa falta era imensamente penoso para Arlinda, constituindo-se na sua principal queixa, principalmente porque tinha acompanhado a trajetória desse neto com muito carinho, conforme podemos ver no turno 06. Ela se perguntava como era possivel esquecer-se do nome desse e se lembrar do de outros.

Para Ponzio (2010, p. 115), ligada à natureza dos nomes próprios está a compreensão de que "o nome é do outro"; ou seja, quem é refe- rido é sempre o outro. De acordo com o autor, a apropriação do nome é "ilusória pretensão da identidade" (PONZIO, 2010, p. 115). Apropriação ilusória porque nenhuma palavra pode ser propriedade de um sujeito. O sujeito tem a ilusão de que possui o nome, ${ }^{7}$ que o nome é seu. Seria mais verdadeiro dizer que o nome, aquele que coincide com o seu "eu", é que define o sujeito para o outro. Para o autor:

Não uso, portanto, o meu nome a não ser para apresentar-me aos outros e para permitir aos outros que me chamem, apontem, localizem. Mas de fato, eu sou meu nome, é o meu nome que me faz existir, que me faz estar na realidade objetiva, é o meu nome que me dá existência objetiva, ou seja, para os outros. [...] "Eu" é um dêitico, é um indicador, indica a mim que sou eu a pronunciá-lo. Em seguida torna-se de um outro, assim que outros o falem (PONZIO, 2010, p. 116).

\section{E, ainda:}

O nome próprio me pertence tanto quanto minha imagem no espelho. É preciso distinguir entre a própria imagem no espelho e imagem especular. A possivel relação entre nome próprio e a imagem própria no espelho não diz respeito àquilo que vejo, quem vejo, quando me ponho diante do espelho, ou seja,

\footnotetext{
Existe uma canção do artista Siba, chamada "A bagaceira", que narra a história de um folião de carnaval que vive a festa de tal forma que seu esquecimento (de si) é completo. Nessa canção, há um trecho que diz: "No fim da bagaceira, minha vista escureceu. Se alguém souber o meu nome, diga pra mim que sou eu" (SIBA, 2012). O autor, em entrevista, revela que essa é uma canção sobre a energia de transfiguração e de renovação, da saúde que vem pela festa e pela alegria, algo que pode ser apreendido no refrão, quando diz que "pode acabar o mundo, vou brincar meu carnaval".
} 
a imagem especular: aquele sou "eu". E se um outro toma meu lugar diante do espelho este "sou eu" será de outro (PONZIO, 2010, p.117).

A relação entre o processo de lembrar e de esquecer não se revela como simétrico. Considerando que toda palavra já tem uma história prévia, um caminho percorrido na história da língua e do sujeito, há na palavra aquilo que desperta memórias e o que permanece no esquecimento, repleto de vozes a serem responsavelmente respondidas no processo de reconfiguração da palavra. Acreditamos que, na rede de enlaces multidimensionais que está subjacente a cada palavra (LURIA, 2001), existem enlaces que estão vivos na memória e outros que estão adormecidos na história e que, ambos, dentro de uma arena em que pesam fatores axiológicos, podem ser mobilizados para sua recuperação. No caso específico de dona Arlinda, a retomada da história no turno 06 (Quadro 2), em respostas aos questionamentos do interlocutor (turno 07 e og), conduz à retomada do nome, junto com o nome do irmão.

No decorrer das sessões fonoaudiológicas foram desenvolvidas duas estratégias para encontrar esse nome, uma de caráter interno, que foi a procura do nome Raimundo, que por vezes a fazia encontrar Rafael, talvez pelo fonema/ grafema inicial, além da história de ambos. A outra estratégia, de caráter externo, não específico para esse nome, foi a construção de um álbum com fotos de familiares e amigos, além de pessoas importantes para Dona Arlinda.

No entanto, não era somente a dificuldade relacionada à linguagem que incomodava dona Arlinda; ela relata que sofria de outros tipos de esquecimento, ainda que em menor grau, relacionados ao fazer cotidiano. Vejamos, no Quadro 3. como a paciente relata essas dificuldades:

Quadro 3 - Recorte de sessão fonoaudiológica 3

\begin{tabular}{|l|l|l|l|l|}
\hline \multicolumn{2}{|c|}{$\begin{array}{c}\text { Data da sessão: } \\
19 / 09 / 2018\end{array}$} & Participantes: Fonoaudiólogo responsável (MVB), Arlinda (A), Estagiárias (AL) e (L) \\
\hline \multicolumn{2}{|c|}{} & $\begin{array}{r}\text { Contexto Situacional - Início de sessão fonoaudiológica, } \\
\text { MVB pergunta sobre os esquecimentos. }\end{array}$ & $\begin{array}{c}\text { Olha, e eu estou assim dentro de casa, as vezes vou fazer alguma coisa... Na } \\
\text { mesma hora que eu vou fazer... eu não estou sabendo o que eu vou fazer... Ai eu } \\
\text { ando pra lá e pra cá, de repente aí eu lembro o que eu ia fazer e não fiz }\end{array}$ \\
\hline A & 01 & Entendi... Como se interrompesse a atividade né, Dona Arlinda? & \\
\hline A & 03 & Me dá aquela coisa assim, na cabeça assim.. Me dá aquele esquecimento. & \\
\hline
\end{tabular}

Fonte: Elaborado pelo autor (2021).

Dona Arlinda estava muito incomodada com esses tipos de esquecimento diários, não diretamente relacionados ao esquecimento de palavras. O auge desses episódios se deu na sessão subsequente, quando relata logo no início da sessão como esqueceu o caminho para chegar ao banheiro, dentro da própria casa, o que para ela era algo exasperador (Quadro 4): 
Quadro 4 - Recorte de sessão fonoaudiológica 4

\begin{tabular}{|c|c|c|c|}
\hline \multicolumn{2}{|c|}{$\begin{array}{l}\text { Data da sessão: } \\
26 / 09 / 2018\end{array}$} & \multicolumn{2}{|c|}{ Participantes: Fonoaudiólogo responsável (MVB), Arlinda (A), Estagiárias (AL) e (L) } \\
\hline & & \multicolumn{2}{|c|}{$\begin{array}{l}\text { Contexto Situacional - Início de sessão fonoaudiológica, } \\
\text { A chega contando um fato novo sobre a memória. }\end{array}$} \\
\hline A & 01 & $\begin{array}{l}\text { Eu fiquei abismada assim, sabe? eu ali dentro da minha } \\
\text { casa, acostumada a rodar ali dentro, pra lá e pra cá, um } \\
\text { monte de mafuá assim na minha frente, eu vou pegando } \\
\text { as coisas e largando assim de lado, e... fiquei assim, sem } \\
\text { saber pra onde eu tava indo, eu sabia que tava indo pro } \\
\text { banheiro, mas não sabia onde era o local do banheiro, não } \\
\text { estava sabendo o local do banheiro }\end{array}$ & $\begin{array}{l}\text { Rindo } \\
\text { Faz gesto com as mãos } \\
\text { como se tentasse pegar } \\
\text { algo no ar }\end{array}$ \\
\hline MVB & 02 & Entendi & \\
\hline A & 03 & Fico nessa de horror... & \\
\hline MVB & 04 & Mas depois lembrou né? & \\
\hline A & 05 & $\begin{array}{l}\text { Eu lembrei porque eu gritei "Maria, chega aqui que eu não } \\
\text { estou sabendo onde é o banheiro". Ai ela já veio correndo... } \\
\text { Mãe, como é que pode acontecer isso? Me puxou pelo } \\
\text { braço e me levou pro meu banheiro. }\end{array}$ & \\
\hline
\end{tabular}

Fonte: Elaborado pelo autor (2021).

Fatos como esse não são incomuns em pessoas com demência de Alzheimer em um estágio mais avançado e, certamente, indicam uma progressão das dificuldades de dona Arlinda. Nesse relato, chamo atenção para o turno 5, de como foi importante para a paciente recorrer à filha como uma forma de se lembrar em que lugar ela estava.

Como expediente terapêutico, tentávamos contornar esses esquecimentos, assim como os relacionados às palavras, com dispositivos para lembrança, desde a confecção parcial do álbum até as dicas de como a paciente poderia se organizar para se lembrar de usar o aparelho auditivo; além de promovermos o desenvolvimento de estratégias que ela poderia usar para se recordar do que necessitava. Outras estratégias eram utilizadas para encontrar as palavras, primeira letra (ex., jenipapo - começa com j), primeiro som, assim como pistas estruturais da palavra (taram taram de Hollanda para Chico Buarque de Hollanda). Todos esses exemplos foram estratégias bem-sucedidas para possibilitar encontrar a palavra, mas como dizia dona Arlinda, com outra pessoa era fácil, difícil é quando está sozinha.

A demanda apresentada por dona Arlinda nos mostra a necessidade de que outras pessoas emprestem suas memórias a outrem, assim como os dispositivos, também, que ofereçam a possibilidade do lembrar. Ao final de uma das sessões, dona Arlinda revelou-me que não tirava mais a foto em que escrevemos o nome do neto da bolsa, pois não queria se esquecer do nome dele nunca mais; "ele está na bolsa, vou lembrar sempre... aí... Não é que ontem quando eu rezei, cadê que eu lembrei dele? Ai fui lá no meu quarto peguei a bolsa, abri a bolsa, lembrei do nome dele" (dona Arlinda, informação verbal, 2019). ${ }^{8}$

\section{Considerações finais}

Por fim, para concluir, devo dizer que esses pontos foram desenvolvidos em torno de pesquisas específicas, de caráter clínico-terapêutico, mas que certamente nos levam a reflexões mais amplas sobre o campo da memória. Cada um desses pontos pode ser ampliado em pesquisas futuras, em outras áreas de conhecimento, sobretudo

8 Trecho retirado de sessão fonoaudiológica, no CREASI, em 25 jul. 2018. 
como uma contribuição aos estudos bakhtinianos.

Pensando com o Círculo de Bakhtin, falar de uma memória absolutamente individual ou coletiva parece algo impossivel, já que a própria constituição do eu se dá na alteridade e, da mesma forma, a memória coletiva não pode. nessa concepção, prescindir de responsividade, atualização, futuridade. A natureza compartilhada das memórias se dá em sujeitos diferentes e em posições axiológicas diferentes. Sendo assim, a existência de uma memória coletiva não se dá em contraposição a uma memória individual, mas composicionalmente com ela, em contraponto, tanto em consonância quanto em dissonância, considerando as diferentes avaliações oriundas dos diferentes posicionamentos em torno do objeto a ser lembrado. O elo entre o individual e o coletivo está no mútuo pertencimento, no terreno interindividual (VOLÓCHINOV, 2017) que atualiza os sentidos das palavras a cada enunciação. Não se trata de uma memória em distribuição, mas de um compartilhamento não coincidente de memórias, de caráter composicional.

Um ponto ainda não desenvolvido, mas bastante saliente em nossa pesquisa atual, em decorrência das particularidades dos sujeitos com sindromes demenciais, seria a possibilidade de se pensar nas especificidades do conceito de Cronotopo para o estudo da memória. Não somente como conceito, mas também como lugar de rememorações em que, impelidos ou não, somos autores. Nesse processo de pesquisa, conhecemos uma paciente que sempre narrava a mesma história, ainda que com modificações mínimas, toda semana, revivendo de maneira sofrida o mesmo fato. Ainda de maneira muito incipiente, acredito que essa temporalidade pode ser analisada em sua natureza cronotópica, mas isso é assunto para o futuro.

\section{Referências}

AMORIM, Marilia. Memória do objeto - uma transposição bakhtiniana e algumas questões para a educação. Bakhtiniana, São Paulo, v. 1, n. 1, p. 8-22, 10 sem. 2009.

BAKHTIN, Mikhail. Estética da Criação Verbal. 2. ed. São Paulo: Martins Fontes, 1997.
BAKHTIN, Mikhail. Para uma filosofia do ato responsável. São Carlos: Pedro e João, 2010.

GERALDI, João Wanderley. Portos de Passagem. São Paulo: Martins Fontes, 1991.

GROISMAN, Daniel. A velhice, entre o normal e o Patológico. História, Ciências, Saúde, Rio de Janeiro, v. 9, n. 1, p. 61-78, jan./abr. 2002.

HALBWACHS, Maurice. A memória coletiva. São Paulo: Centauro, 2017.

HANLEY, Richard. Retrieval failures for the names of familiar people. In: SCHWARTZ, Bennett L., BROWN, Alan S. Tip-of-the-tongue states and related phenomena. Cambridge University Press, 2014. p. 1244-1824. E-book.

JAMES, Willian. Principles of psychology. New York: Holt, 1890 .

LURIA, Alexander Romanovich. Pensamento e Linguagem: As últimas conferências de Luria. São Paulo: Ed. Artmed. 2001.

NOVAES-PINTO, Rosana do Carmo. A contribuição do estudo discursivo para uma análise crítica das categorias clinicas. Tese (Doutorado em Linguistica) - Instituto de Estudos da Linguagem, Universidade Estadual de Campinas, Campinas, SP, 1999.

OLIVEIRA, Marcus Vinicius Borges. Palavras na ponta-da-lingua: uma abordagem neurolinguística Tese (Doutorado em Linguística) - Instituto de Estudos da Linguagem, Universidade Estadual de Campinas, Campinas, SP, 2015.

OLIVEIRA. Marcus Vinicius Borges. Palavras na ponta-da-lingua: uma abordagem neurolinguística. São Carlos: Pedro e João 2017.

PONZIO, Augusto. Linguistica generale, scrittura letteraria e traduzione. Perugia: Guerra Edizioni, 2007.

PONZIO, Augusto. Procurando uma palavra outra. São Carlos: Pedro e João, 2010.

A BAGACEIRA. Intérprete: SIBA. Compositor: Sérgio Roberto Veloso de Oliveira In: AVANTE. Intérprete: Siba. Fina Produção: Mata Norte, 2012. faixa 5.

VOLÓCHINOV, Valentin. Marxismo e Filosofia da Linguagem. Problemas fundamentais do método sociológico na ciência da linguagem. São Paulo: Editora 34, 2017. 373 p.

WERTSCH, James V. Texto e dialogismo no estudo da memória coletiva. Educação e Pesquisa, São Paulo, v. 36, p. 123-132, 2010.

\section{Marcus Vinicius Borges Oliveira}

Doutor em Linguistica pelo Instituto de Estudos da Linguagem (IEL) da Universidade Estadual de Campinas (UNICAMP), em Campinas, SP, Brasil; mestre em Letras e Linguistica pela Universidade Federal da Bahia (UFBA), em Salvador, BA, Brasil; graduado no Bacharelado de Fonoaudiologia da UFBA; professor adjunto do Departamento de Fonoaudiologia da UFBA e do Programa de Pós-Graduação em Educação da Faculdade de Educação da UFBA, em Salvador, BA, Brasil. 


\section{Endereço para correspondência}

Marcus Vinicius Borges Oliveira

Universidade Federal da Bahia

Instituto de Ciências da Saúde

Departamento de Fonoaudiologia

Av. Reitor Calmon, s/n

40231-300

Salvador, BA, Brasil

Os textos deste artigo foram revisados pela Poá Comunicação e submetidos para validação do autor antes da publicação. 